\title{
Erratum to: An approach to conversational agent design using semantic sentence similarity
}

\author{
Karen O'Shea · Keeley Crockett · Zuhair Bandar . \\ James O'Shea
}

Published online: 26 October 2013

(C) Springer Science+Business Media New York 2013

Erratum to: Appl Intell (2012) 37:558-568

DOI 10.1007/s10489-012-0349-9

The original version of this article unfortunately contained a mistake. The original article was submitted with Karen O'Shea as a sole author. There were however, additional authors whom should have received credit. The authors: Keeley Crockett, Zuhair Bandar and James O'Shea are now included as authors of the above publication.

The online version of the original article can be found under doi:10.1007/s10489-012-0349-9.

K. O'Shea ( $\varangle)$

School of Computing, Mathematics and Digital Technologies,

Manchester, UK

e-mail: Kaz.oshea@yahoo.co.uk

K. Crockett $\cdot$ Z. Bandar $\cdot$ J. O'Shea

Manchester Metropolitan University, John Dalton Building,

Manchester, UK

K. Crockett

e-mail: k.crockett@mmu.ac.uk

Z. Bandar

e-mail: z.bandar@mmu.ac.uk

J. O'Shea

e-mail: j.d.oshea@mmu.ac.uk 